\title{
POET'S CORNER
}

Julia Giesen, NIDCAP Professional

Edmonton, Canada

$\mathrm{H}$ ello again from Edmonton! Julia Giesen here with a second reflection to share from my NIDCAP training. This poem is from an observation in July 2019, this time on a little boy named Benson. Benson was born at 30 weeks and was six days old. For this observation my trainer asked me to think about what I would like to communicate to the nurse looking after him in the NICU. I watched as little Benson paused in his breathing for longer and longer, dropping off to become unavailable. I recalled my NIDCAP Trainer saying one goal of every newborn is to interact with his or her caregivers. I had so many questions running through my head.

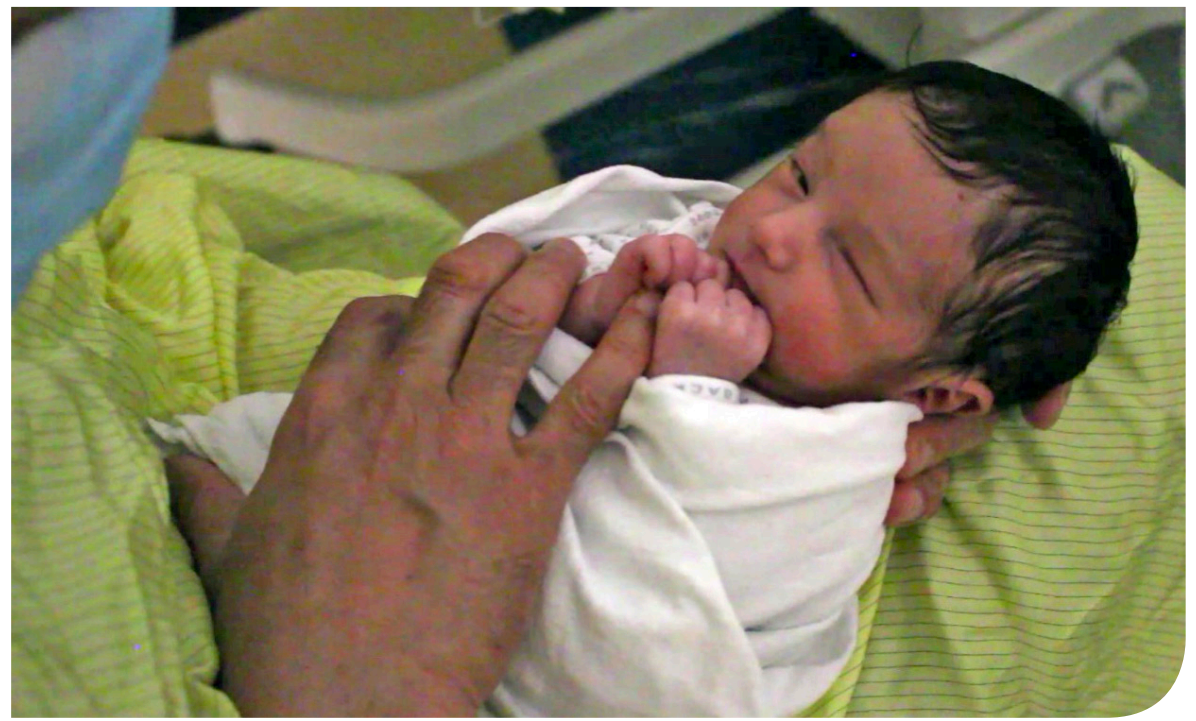

\section{"What Can I Say?"}

Today I tried something new

To change my usual point of view From seeing through the baby's eyes To focus on what I could surmise For tips and tricks I could relay To nurses to improve their day

What could I glean from what I feel

This little one tries to reveal What kind of help does he need How can I teach a nurse to read His cues and signs of hanging on Keeping it together, then moving on

Slipping down, losing touch When all of it becomes too much When breathing pauses get drawn out And he has nothing left to shout That he really needs our help But has no energy to yelp
How can we leave him at his best

So he can breathe and get some rest Moving softly into sleep That is robust, healing and deep So that when he does awaken Energy is not from him taken

To open his eyes and turn his head And look up out of his bed And meet the eyes he's coming to know Will be there always to watch him grow —Julia Giesen 